\title{
O que falam os trabalhos sobre Prática como Componente Curricular?
}

\section{What do the papers on Practice as a Curricular Component say?}

\author{
Jaiane de Moraes Boton (jaiambbio@gmail.com) \\ Universidade Federal de Santa Maria, UFSM \\ Luiz Caldeira Brant de Tolentino-Neto (lcaldeira@ smail.ufsm.br) \\ Universidade Federal de Santa Maria, UFSM
}

Resumo: A Prática como Componente Curricular, oportunidade de ligação entre as disciplinas de conteúdo específico e aquelas de conteúdo pedagógico, é de suma importância à formação docente inicial. Além disso, ela deve oportunizar o desenvolvimento de competências e habilidades necessárias à atividade docente. Considerando a importância dessa Prática na formação de professores temos como objetivo no presente trabalho mapear e investigar publicações que têm como foco a Prática como Componente Curricular. Para tanto, fizemos o levantamento de dissertações, teses e artigos relacionados a esse tema publicados nos últimos 10 anos. Analisamos 16 dissertações, 12 teses e 16 artigos. Os trabalhos apontam que, mesmo havendo o conhecimento das legislações relacionadas à PCC, ainda há uma falta de entendimento sobre o que é e como a PCC pode ser desenvolvida. Além disso, muitos trabalhos analisam os Projetos Pedagógicos de Cursos com a intenção de saber como a PCC é desenvolvida. Muitas vezes o que se mostra é que documentalmente os cursos estão em consonância com a legislação, no entanto, quando ocorrem entrevistas com alunos e professores, são vistas fragilidades na implementação da Prática. Muitos alunos desconhecem e/ou confundem a PCC com o Estágio e ainda há uma falta de envolvimento dos professores para o desenvolvimento de trabalhos em disciplinas voltadas à PCC.

Palavras-chave: prática como componente curricular; formação de professores.

Abstract: The Practice as a Curricular Component is of great importance since it provides the link between the disciplines of specific content and those of pedagogical content. In addition, it should provide the development of skills and abilities necessary for the teaching activity. Considering the importance of this practice in teacher training, we aim to investigate publications that focus on practice as a curricular component. To do so, we did the survey of dissertations, theses and articles related to this topic. We analyzed 16 dissertations, 12 theses and 16 articles. The work shows that, even though there is knowledge of legislation related to the PCC, there is still a lack of understanding about 
what PCC is and how it can be developed. In addition, many papers analyze the PPCs of the courses with the intention of knowing how the PCCis developed, often what is shown is that the courses are documentary in line with the legislation. However, when interviews with students and teachers occur, weaknesses are seen in the implementation of the Practice. Many students are unaware of and / or confuse the CCP with the Internship and there is still a lack of involvement of teachers in the development of work in PCC disciplines.

Keywords: practice as a curricular component; teacher training.

\section{INTRODUÇÃO}

O termo Prática como Componente Curricular (PCC) foi utilizado pela primeira vez na Parecer CNE/CP 28/2001 que deu origem à Resolução CNE/CP 2/2002, a qual define a carga horária para os cursos de Formação de Professores da Educação Básica, em nível superior, em curso de licenciatura plena. O termos utilizado no Pareceres CNE/CP 9/2001 e na Resolução CNE/CP 1/2002 era somente prática, tal como podemos ver na definição presente no parecer

Uma concepção de prática mais como componente curricular implica vê-la como uma dimensão do conhecimento que tanto está presente nos cursos de formação, nos momentos em que se trabalha na reflexão sobre a atividade profissional, como durante o estágio, nos momentos em que se exercita a atividade profissional. (BRASIL, 2001, p.23)

Já no Parecer CNE/CP 21/2001 o termo utilizado é Prática de Ensino. Posteriormente esse termo foi modificado pelo Parecer CNE/CP 28/2001 que deu nova redação ao parecer anterior que o define da seguinte maneira.

A prática como componente curricular é, pois, uma prática que produz algo no âmbito do ensino. Sendo a prática um trabalho consciente cujas diretrizes se nutrem do Parecer 9/2001 ela terá que ser uma atividade tão flexível quanto outros pontos de apoio do processo formativo, a fim de dar conta dos múltiplos modos de ser da atividade acadêmico-científica. Assim, ela deve ser planejada quando da elaboração do projeto pedagógico e seu acontecer deve se dar desde o início da duração do processo formativo e se estender ao longo de todo o seu processo. Em articulação intrínseca com o estágio supervisionado e com as atividades de trabalho acadêmico, ela concorre conjuntamente para a formação da identidade do professor como educador (BRASIL, 2001, p.09). 
O Parecer 2/2015, considerado na Resolução CNE/CP 2/2015, utiliza como caracterização da prática como componente curricular tal como delineado no Parecer CNE/CP 9 e 28/2001 e reforçado no Parecer CNE/CES 15/2005.

Ao tratar do eixo articulador das dimensões teóricas e práticas, o Parecer CNE/CP 9/2001 afirma

Assim, a prática na matriz curricular dos cursos de formação não pode ficar reduzida a um espaço isolado, que a reduza ao estágio como algo fechado em si mesmo e desarticulado do restante do curso. (...) Nessa perspectiva, o planejamento dos cursos de formação deve prever situações didáticas em que os futuros professores coloquem em uso os conhecimentos que aprenderem, ao mesmo tempo em que possam mobilizar outros, de diferentes naturezas e oriundos de diferentes experiências, em diferentes tempos e espaços curriculares. (BRASIL, 2001, p.57)

Já o Parecer CNE/CP 28/2001, ao justificar a carga horária dedicada à prática, enuncia

Assim, há que se distinguir, de um lado, a prática como componente curricular e, de outro, a prática de ensino e o estágio obrigatório definidos em lei. A primeira é mais abrangente: contempla os dispositivos legais e vai além deles. A prática como componente curricular é, pois, uma prática que produz algo no âmbito do ensino (...) É fundamental que haja tempo e espaço para a prática, como componente curricular, desde o início do curso (...) (BRASIL, 2001, p.09)

O Parecer CNE/CES 15/2005 esclarece que

a prática como componente curricular é o conjunto de atividades formativas que proporcionam experiências de aplicação de conhecimentos ou de desenvolvimento de procedimentos próprios ao exercício da docência. Por meio destas atividades, são colocados em uso, no âmbito do ensino, os conhecimentos, as competências e as habilidades adquiridos nas diversas atividades formativas que compõem o currículo do curso. As atividades caracterizadas como prática como componente curricular podem ser desenvolvidas como núcleo ou como parte de disciplinas ou de outras atividades formativas. Isto inclui as disciplinas de caráter prático relacionadas à formação pedagógica, mas não aquelas relacionadas aos fundamentos técnico-científicos correspondentes a uma determinada área do conhecimento. (BRASIL, 2005, p. 03)

A PCC é de suma importância visto que propicia a ligação entre as disciplinas de conteúdo específico e aquelas de conteúdo pedagógico. Além disso, deve oportunizar o desenvolvimento de competências e habilidades necessárias à atividade docente. Contudo sua inserção curricular, objetivos, conteúdos e formatos ainda são assuntos controversos em muitos cursos (PEREIRA; MOHR, 2013, p.02). 
Conforme exposto por Terrazzan et al (2008)

as atividades relativas à PCC deverão se constituir em momentos de formação privilegiados para articular o conhecimento conceitual da "matéria de ensino" com os conteúdos a serem ensinados na Educação Básica, considerando condicionantes, particularidades e objetivos de cada unidade escolar. (TERRAZZAN; DUTRA; WINCH; SILVA, 2008, p.75)

Considerando a importância da Prática como Componente Curricular na formação de professores temos como objetivo no presente trabalho de investigar publicações, artigos, dissertações e teses, que têm como foco a Prática como Componente Curricular.

\title{
2. DESENVOLVIMENTO DA PESQUISA DO ESTADO DO CONHECIMENTO
}

A presente pesquisa se enquadra, quanto aos seus objetivos, como uma pesquisa de estado de conhecimento. Segundo Ferreira (2002) essas pesquisas são definidas como de caráter bibliográfico e tem como função mapear e discutir uma certa produção acadêmica em diferentes campos do conhecimento.

Além disso, tais pesquisas estão

\begin{abstract}
tentando responder que aspectos e dimensões vêm sendo destacados e privilegiados em diferentes épocas e lugares, de que formas e em que condições têm sido produzidas certas dissertações de mestrado, teses de doutorado, publicações em periódicos e comunicações em anais de congressos e de seminários. Também são reconhecidas por realizarem uma metodologia de caráter inventariante e descritivo da produção acadêmica e científica sobre o tema que busca investigar, à luz de categorias e facetas que se caracterizam enquanto tais em cada trabalho e no conjunto deles, sob os quais o fenômeno passa a ser analisado. (FERREIRA, 2002, p. 258)
\end{abstract}

Para um melhor entendimento dividimos nosso trabalho em duas partes: levantamento de teses e dissertações, e levantamento de artigos em periódicos acadêmicos. A seguir explicamos como procedemos em cada uma dessas etapas.

\section{a. O levantamento de dissertações e teses.}

Acessamos, em novembro de 2018, o Catálogo de teses e dissertações da CAPES para realizar uma busca de trabalhos que continham o termo "Prática como Componente 
Curricular" publicados entre os anos de 2013 a 2018. Nosso ponto de partida foi o ano de 2013, pois foi esse o ano em que o catálogo passou a disponibilizar online informações mais completas dos trabalhos.

Inicialmente, encontramos ao total 42 trabalhos, sendo 28 dissertações e 14 teses. O resumo de cada um dos trabalhos encontrados foi lido e catalogado. Excluímos de nossa análise, das 28 dissertações inicialmente encontradas, 12 trabalhos, pois não tratavam do assunto, restando para o nosso estudo 16 dissertações. E dentre as 14 teses encontradas, duas foram excluídas por não tratarem do assunto, restando 12 teses que tiveram seus resumos analisados.

Organizamos os trabalhos analisados de acordo com a proximidade de seus resultados e salientados que não fizemos distinção entre dissertações e teses.

\section{b. O levantamento dos artigos.}

Acessamos, em outubro de 2018, o Portal de Periódicos da Capes, por ser um meio disponibilizado pela instituição, e fizemos a busca de artigos publicados nos últimos 10 anos, que continham o termo "Prática como Componente Curricular", no título ou assunto.

Inicialmente obtivemos 22 artigos. Após a leitura dos resumos, retiramos seis artigos, que não abordavam o tema buscado, restando 16 artigos que foram lidos na íntegra. Quanto à classificação Qualis CAPES 2013-2016, na área de Ensino, das revistas às quais pertenciam os artigos analisados, temos: duas revistas classificadas como A1, cinco como A2, três como B1, duas como B2, uma como B3, e três não havia classificação no Qualis Ensino 2013-2016.

Organizamos os trabalhos selecionados de acordo com o tipo de fontes utilizadas, documentos e sujeitos, e as relações realizadas pelos autores.

\section{DO QUE TRATAM AS TESES E DISSERTAÇÕES ENCONTRADAS}

Segundo Hoffmann (2016) são poucos os estudos sobre como a Prática como Componente Curricular que podem colaborar com a formação da identidade profissional dos futuros docentes. 
Alguns trabalhos (MONTEIRO, 2013; SILVA, 2013; RESENDE, 2015; OLIVEIRA-NETO, 2016; OMELCZUK, 2017) analisaram a carga horária da PCC em diferentes cursos, tais trabalhos mostraram que os cursos atendem ou ultrapassam a carga horária prevista para a PCC nas legislações. Outros trabalhos (OLIVEIRA-NETO, 2016; ALMEIDA, 2016; FERREIRA, 2015; PREUSSLER, 2017) que a Prática se organiza de diferentes formas, tanto com disciplinas exclusivas ou dentro de disciplinas pedagógicas ou específicas. E que diferentes atividades são desenvolvidas para o desenvolvimento da PCC (MONTEIRO, 2013; ROCHA, 2016; VIANA, 2017; FIGUEIREDO, 2015).

Além disso, pesquisas mostram que existem dúvidas sobre o que realmente seja a Prática como Componente Curricular e que existem diferentes interpretações das legislações (OLIVEIRA, 2015; BARBOSA, 2015; PEREIRA, 2016, GRANZOTO, 2017 e TAGLIATI, 2013). Há uma deficiência na articulação entre teoria e prática na ação pedagógica, gerando dificuldade em implementar a PCC nos cursos por vários motivos: falta de professores na área de ensino, desvalorização do ensino, falta de participação de professores da área de ensino na formulação de projetos e de disciplinas relacionadas à PCC (RESENDE, 2015; OLIVEIRA-NETO, 2016; ROCHA, 2016; OMELCZUK, 2017; VILLANI, 2014; SILVERIO, 2014; FERREIRA, 2015; LEAL, 2016; SILVA, 2016).

Em seu trabalho, Silva (2014) constata que a Prática, em alguns casos, dá ênfase ao conhecimento teórico, tanto específico quanto pedagógico, distorcendo assim o que rezam as legislações.

Há um desconhecimento dos alunos acerca da Prática como Componente Curricular, muitos a confundem com o Estágio Curricular Supervisionado (MOREIRA, 2017; SANTOS, 2017; BISCONSINI, 2017).

Quanto aos docentes, eles reconhecem que há uma lacuna entre o que a legislação pede e o que é implementado nos cursos (MELO, 2018; OLIVEIRA, 2015; BARBOSA, 2015). Também é reconhecida uma lacuna nos currículos em relação à PCC e que os docentes a utilizam para desenvolver materiais didáticos (PEREIRA, 2016). Segundo Sarro (2014), os professores destacam a importância da PCC na formação inicial desde que seja melhor organizada. 
Em seu trabalho, Oliveira-Neto (2016), percebe que a relação teoria-prática é manifestada nos PPC, contudo as aproximações com um fazer e saber práxico são em sua maioria ausentes; os cursos cumprem a carga horária de 400h de PCC exigida pela legislação; a abordagem do componente está ligada a uma concepção de interdisciplinaridade, sendo entendido também como um espaço de aprendizagem acerca da transformação do conhecimento científico em conhecimento escolar.

E Preussler (2017) constatou que a proposta integradora da PCC mobiliza uma reorganização diferente do processo de formação de professores de Matemática do IFFar: uma reorganização que traz consequências às ações da gestão dos cursos, bem como exige outras ações pedagógicas aos formadores. Evidencia-se, também, a emergência de um paradigma diferente do convencionalmente realizado na formação de professores. Mesmo assim a pesquisa aponta que é possível e necessário avançar na construção de significados da proposta integradora da PCC de modo que transcenda a discussão acadêmica e a legislação e se materialize em ações pedagógicas no processo de formação. Tais ações necessitam ser pautadas pelo diálogo reflexivo entre a teoria e a prática da docência na formação e estar integradas às escolas de formação (licenciatura e escola de educação básica).

\section{DO QUE TRATAM OS ARTIGOS ENCONTRADOS}

Em seu trabalho, Nascimento (2013) analisa a legislação que orienta a formação de professores no Brasil e apresenta as dificuldades para efetivar as solicitações contidas nas diretrizes. Para ele a Prática como Componente Curricular é uma grande oportunidade para o professor construir práticas ligadas ao ensino, repensando a própria dinâmica no Ensino Superior à luz daquela voltada para os ensinos Médio e Fundamental.

Zabel e Malheiros (2018) discute os conceitos de PCC existentes, tanto em documentos legais como em pesquisas, também observou dificuldades e distorções quanto à implementação da PCC, e defende sua importância para superar a dicotomia entre conhecimento específico e conhecimento pedagógico.

Já Santos e Mesquita (2018) além de analisarem a legislação relacionada à PCC e o Estágio Curricular Supervisionado nos cursos de licenciatura em Química, buscaram 
relacioná-los à concepção dos alunos sobre a Prática, e perceberam a falta de compreensão e, até certo ponto, de distinção entre PCC e Estágio.

Em seu levantamento de pesquisas referentes à formação de professores no período entre 2005 a 2014, especialmente as produções que abordam o Estágio Curricular Supervisionado e a Prática como Componente Curricular, Maffei (2014) percebeu que as potencialidades atribuídas aos componentes curriculares relacionam-se à capacidade de colocar o futuro professor em contato com a experiência de ser professor, possibilitando a aproximação dos conteúdos de formação à atuação profissional. No entanto, nota-se o entrave que é a existência de um currículo, ainda, tecnicista e fragmentado da formação e os conteúdos veiculados às disciplinas que, muitas vezes, se limitam a apresentação de práticas já superadas.

Rodrigues e Hentz (2011) analisam a matriz curricular de três cursos de universidades em Santa Catarina e constaram que as PCC são implementados de diferentes formas: diferentes disciplinas; de modo interdisciplinar; e disciplinas específicas.

Já Costa e Tiago (2017) realizaram a construção da concepção de PCC em projetos pedagógicos, mas não tivemos acesso ao trabalho completo, somente ao resumo.

Kasseboehmer e Farias (2012) descrevem qualitativamente quais conteúdos são considerados nas disciplinas associadas à carga horária de Prática como Componente Curricular (PCC) e analisa como este aspecto da formação está sendo considerado nos cursos de Licenciatura em Química nas Regiões Norte e Sudeste do País. Por meio da análise dos PPC, matrizes curriculares e ementas de disciplinas, os autores relatam que muitas vezes a PCC não estava clara e, mesmo assim, há uma variedade de conteúdos que promovem a integração entre os conhecimentos químicos e pedagógicos e têm como objeto de estudo os aspectos específicos da aprendizagem de química na sala de aula com uma perspectiva crítica e de pesquisa.

Brandalise e Trobia (2011), a partir análise do PCC e entrevistas realizadas com professores e discentes durante o processo de reformulação curricular do curso de Licenciatura em Matemática de uma universidade pública paranaense, investigaram a contribuição das disciplinas de Instrumentação para o Ensino de Matemática para a 
formação inicial e perceberam que as disciplinas oportunizam aos acadêmicos desde o início do curso o envolvimento com atividades de docência. No entanto, algumas fragilidades também foram percebidas: docentes despreparados, articulação precária das disciplinas, ausência de professores em reuniões, deficiência das ementas das disciplinas quanto aos conteúdos necessários para a formação docente específica, desvalorização da disciplina pelos alunos e docentes.

Silva, Jófili e Carneiro-Leão (2014) investigaram o potencial da PCC na formação de professor de biologia. Para seu estudo, analisaram o PPC e entrevistaram professores e estudantes e perceberam incoerências entre o descrito nos documentos, o discurso dos docentes e a percepção dos estudantes. No entanto, apesar dessas incoerências, há ênfase ao conhecimento teórico do conteúdo específico e do pedagógico e a mobilização das competências pedagógicas e da reflexiva.

Calvo e Freitas (2011) entrevistaram docentes para conhecer suas compreensões sobre a PCC e como eles implementam em sala de aula, e perceberam que os docentes reconhecem a importância e a necessidade de se contemplar a PCC desde o início do curso e de procurarem desenvolver atividades para que isso se efetue. No entanto, não foram observados propostas ou relatos de Prática que sinalizem um trabalho colaborativo com o contexto da educação básica. Considerando necessário se ter clareza do conceito de transposição didática para o trabalho com a prática como componente curricular, bem como a necessidade e a relevância de ações coletivas entre os docentes para que haja um efetivo envolvimento e comprometimento com a formação docente inicial.

Bisconsini e Oliveira (2018) analisaram a PCC no processo de formação inicial em Educação Física - Licenciatura a partir de entrevistas com acadêmicos e docentes. Seus resultados mostraram que os discentes entrevistados demonstraram desconhecer a PCC, o que não foi evidenciado pelos docentes, que apesar de reconhecerem a lacuna existente no currículo pela ausência desse componente, apresentam-se predispostos a organizá-lo no curso.

Ao analisar a relação entre teoria e prática em disciplinas, Viana, Munford, Pereira e Moro (2012), perceberam que os professores acabam se preocupando pouco com as relações que o conhecimento científico estabelece com outras formas de conhecimento, 
sobretudo os escolares e educacionais. Mas que, mesmo mantendo o conhecimento biológico como central, houve reconhecimento da importância de conhecimentos acerca dos alunos e da escola.

Em trabalho posterior, Viana, Munford, Ferreira e Fernandes (2015) analisaram a construção de relações teoria-prática na formação de professores de Ciências e perceberam que as relações teoria-prática são construídas em vários espaços/tempos da formação de professores, em especial, quando são estabelecidos debates em torno das atividades do professor na escola. Identificaram, também que nesta construção os participantes mobilizam experiências, vivenciadas ou imaginadas.

Pereira e Velasco (2015) notaram que as disciplinas analisadas constituem dimensões práticas que têm sua autonomia e, ao mesmo tempo, dialogam umas com as outras.

Brito (2017) analisou como os Cursos de Licenciaturas interdisciplinares da Universidade Federal do Sul da Bahia (UFSB) "obedecem" às dimensões quantitativas atribuídas pelas normativas vigentes (quantitativos de horas, suas distribuições entre as dimensões curriculares exigidas formalmente) e percebe que na mesma operação em que presta obediência às normas vigentes, subverte-as, em nome da inovação, da singularidade e originalidade atribuídas a esses cursos.

Chrysostono e Messeder (2017) analisaram o viés pedagógico de propagandas televisivas em oficinas pedagógicas. Foi percebido que além da base teórica é preciso que o professor compreenda sua função no alicerce de seu trabalho, o que só seria possível pelo contato com a prática em sala de aula desde os primeiros instantes de sua formação. É salientado que a compreensão da inserção da PCC na formação de professores ainda não foi bem compreendida pelos professores formadores como aproximadora da realidade escolar para o professor em formação.

\section{CONSIDERAÇÕES FINAIS}

Observamos que alguns autores deram continuidade nos trabalhos com a PCC, já que dois autores analisados publicaram teses e artigos: Bisconsini com sua tese em 2017 
e um artigo em 2018, e Viana com a tese em 2014, um artigo em 2012 e outro artigo em 2015. E outros dois autores que publicaram dissertação e artigo com a mesma temática: Santos com sua dissertação em 2017 e um artigo em 2018; e Silva publicou sua dissertação 2013 e um artigo em 2014. Fato que é importante para o desenvolvimento da pesquisa sobre essa temática.

A partir da análise dos trabalhos analisados, teses, dissertações e artigos, percebemos que, mesmo havendo o conhecimento das legislações relacionadas à PCC, há, ainda, falta de entendimento sobre o que é e como a PCC pode ser desenvolvida. Para preencher essa lacuna, acreditamos que seja necessário ocorrer uma formação complementar aos docentes e um estudo mais aprofundado das legislações para que elas sejam melhor compreendida.

Constatamos que muitos trabalhos analisaram os PPC dos cursos com a intenção de saber como ela é desenvolvida, e notaram que os cursos estão documentalmente em consonância com a legislação. No entanto, quando ocorrem entrevistas com alunos e professores, são vistas fragilidades na implementação da Prática, pois muitos alunos desconhecem e/ou confundem a PCC com o Estágio e ainda há uma falta de envolvimento dos professores para o desenvolvimento de trabalhos em disciplinas voltadas à PCC.

Entendemos que há uma necessidade de envolvimento dos docentes para o desenvolvimento da PCC, tanto dos professores responsáveis pelas disciplinas específicas da matéria de ensino como das disciplinas pedagógicas. Uma possibilidade seria a criação de uma comissão de estudos sobre possibilidades de desenvolvimento da PCC de maneira que prepare melhor o futuro professor em sua atuação, além de fazer com que o licenciando se reconheça como professor desde o início do curso.

\section{AGRADECIMENTOS}

Ao Programa de Pós-graduação em Educação em Ciências: Química da Vida e Saúde da UFSM, e à Coordenação de Aperfeiçoamento de Pessoal de Nível Superior (CAPES). 


\section{REFERÊNCIAS UTILIZADAS NO TRABALHO}

BRASIL. Conselho Nacional de Educação. Parecer CNE/CP 28/2001, de 2 de outubro de 2001. Dá nova redação ao Parecer CNE/CP 21/2001, que estabelece a duração e a carga horária dos cursos de Formação de Professores da Educação Básica, em nível superior, curso de licenciatura, de graduação plena. Publicado no Diário Oficial da União de 18/01/2002.

BRASIL. Parecer CNE/CES 2, de 2 fevereiro de 2005. Solicitação de esclarecimento sobre as Resoluções CNE/CP n ${ }^{\circ}$ s 1/2002, que institui Diretrizes Curriculares Nacionais para a Formação de Professores da Educação Básica, em nível superior, curso de licenciatura, de graduação plena, e 2/2002, que institui a duração e a carga horária dos cursos de licenciatura, de graduação plena, de Formação de Professores da Educação Básica, em nível superior . Diário Oficial União. 02.fev,2005. Disponível em: <http://portal.mec.gov.br/cne/arquivos/pdf/pces0015_05.pdf>. Acesso em: 22.jan.18. BRASIL. Parecer CNE/CP 09 de 08 de maio de 2001, publicado em 18 de janeiro de 2002. Proposta de Diretrizes Curriculares Nacionais para a formação de Professores da educação básica, em nível superior, curso de licenciatura, de graduação plena. Diário Oficial da União, Brasília, DF, 2001. Disponível em: <http://portal.mec.gov.br/cne/arquivos/pdf/009.pdf $>$. Acesso em: 22.jan.2018. FERREIRA, N. S. A.. As pesquisas denominadas "estado da arte". Educação e Sociedade, Campinas, SP , v. 23, n. 79, p. 257-272, ago. 2002. Disponível em: $<$ http://www.scielo.br/scielo.php?script=sci_arttext\&pid=S010173302002000300013\&lng=en\&nrm=iso >. Acesso em: 01.mar.2019. http://dx.doi.org/10.1590/S0101-73302002000300013.

PEREIRA, B.; MOHR, A. Prática como Componente Curricular em cursos de Licenciatura de Ciências Biológicas no Brasil. Atas do IX Encontro Nacional de Pesquisa em Educação em Ciências - IX ENPEC. Águas de Lindóia, SP, 10-14 nov.2013.

TERRAZZAN, E. A.; DUTRA, E. F.; WINCH, P. G.; SILVA, A. A. Configurações curriculares em cursos de licenciatura e formação identitária de Professores. Diálogo Educacional, v. 8, n. 23, 2008, p.71-90. Disponível em: 
<https://periodicos.pucpr.br/index.php/dialogoeducacional/article/view/3973/3889> Acesso em: 15 mar. 2018

\section{REFERÊNCIAS DOS TRABALHOS ANALISADOS}

ALMEIDA, S. A prática como componente curricular nos cursos de formação de professores de química no estado de Goiás. 2016. Dissertação (Mestrado em Educação em Ciências e Matemática) - Universidade Federal de Goiás, Goiânia, 2016. Disponível em:

<https://repositorio.bc.ufg.br/tede/bitstream/tede/5882/5/Disserta\%C3\%A7\%C3\%A3o \%20-\%20Sara\%20de\%20Almeida\%20-\%202016.pdf >. Acesso em: 20 nov.2018

BARBOSA, A. T.. Sentidos da prática como componente curricular na licenciatura em ciências biológicas. 2015. 174 f. Dissertação (Mestrado em Educação Científica e Tecnológica) - Universidade Federal de Santa Catarina, Florianópolis, 2015. Disponível em:

$<$ https://repositorio.ufsc.br/bitstream/handle/123456789/136316/335940.pdf?sequence= 1\&isAllowed=y>. Acesso em: 20 nov.2018

BISCONSINI, C. R.. A prática como componente curricular na formação inicial de professores de Educação Física: ruídos no campo universitário para o encontro com a escola. 2017. 409 f. Tese (Doutorado em Educação Física) - Universidade Estadual de Maringá, 2017.

BISCONSINI, C. R.; OLIVEIRA, A. A.B.. A prática como componente curricular na formação inicial de professores de Educação Física. Movimento (ESEFID/UFRGS), Porto Alegre, v. 24, n. 2, p. 455-470, abr/jun. 2018. ISSN 1982-8918. Disponível em: <https://seer.ufrgs.br/Movimento/article/view/76705>. Acesso em: 26 nov. 2018. doi:https://doi.org/10.22456/1982-8918.76705.

BRANDALISE, M. A. T.; TROBIA, J.. A Prática como Componente Curricular na Licenciatura em Matemática: Múltiplos Contextos, Sujeitos e Saberes. Educação Matemática Pesquisa: Revista do Programa de Estudos Pós-Graduados em Educação Matemática, [S.1.], v. 13, n. 2, p. 273-289, jul. 2011. ISSN 1983-3156. Disponível em: <https://revistas.pucsp.br/emp/article/view/6248>. Acesso em: 26 nov. 2018. 
BRITO, E. P. P. E.. A Universidade Federal do Sul da Bahia (UFSB) e o projeto universidade nova: como ficam as licenciaturas?. Revista Internacional de Educação Superior, Campinas, SP, v. 3, n. 3, p. 563-581, ago. 2017. ISSN 2446-9424. Disponível em:

<https://periodicos.sbu.unicamp.br/ojs/index.php/riesup/article/view/8650623/16836>. Acesso em: 26 nov. 2018. doi:https://doi.org/10.22348/riesup.v3i3.7779.

CALVO, L. C. S.; FREITAS, M. A.. Prática como componente curricular e sua implementação em sala de aula na visão de formadores de um curso de Letras. Acta Scientiarum. Language and Culture (UEM), Maringá, vol. 33, n. 2, p. 315, jul/dez. 2011. ISSN 1983-4683. Disponível em:

<http://www.periodicos.uem.br/ojs/index.php/ActaSciLangCult/article/view/13798/139 78>. Acesso em: 26 nov. 2018.

CHRYSOSTOMO, T. S.; MESSEDER, J. C.. Uma visão sobre a Prática como Componente Curricular utilizando oficinas pedagógicas e recursos midiáticos no Ensino de Química. Revista Internacional de Formação de Professores, [S.1.], vol. 2, n. 4, p. 139-155, jan. 2017. ISSN 2447-8288. Disponível em: <https://periodicos.itp.ifsp.edu.br/index.php/RIFP/article/view/607>. Acesso em: 26 nov. 2018.

COSTA, N. F.; TIAGO, G. M.. A prática como componente curricular nos cursos de licenciatura em Matemática do IFSP. Revista UniVap, São José dos Campos, SP, v. 22, n. 40, Edição Especial, 2016. ISSN 2237-1753. Disponível em: <https://revista.univap.br/index.php/revistaunivap/article/view/1167/948>. Acesso em: 26 nov. 2018. DOI: http://dx.doi.org/10.18066/revistaunivap.v22i40.1167.

FERREIRA, A. R.. Entre as práticas das teorias e vice-versa - a prática de ensino como componente curricular nas licenciaturas em História no Brasil após 2002. 2015. 202 f. Tese (Doutorado em Educação) - Universidade Estadual de Ponta Grossa, Ponta Grossa, 2015. Disponível em:

<http://tede2.uepg.br/jspui/bitstream/prefix/1185/1/Angela\%20Ribeiro\%20Ferreira.pd>. Acesso em: 20 nov.2018 
FIGUEIREDO, S. A.. Formação inicial de professores e a integração da prática como componente curricular na disciplina de matemática elementar. 2015. $308 \mathrm{f}$. Tese (Doutorado em Educação Matemática) - Universidade Anhanguera de São Paulo, São Paulo, 2015. Disponível em: <https://docplayer.com.br/27922092-Universidadeanhanguera-de-sao-paulo-sonner-arfux-de-figueiredo.html>. Acesso em: 20 nov.2018 GRANZOTO, B.. A prática como componente curricular na formação de professores em cursos de licenciatura em educação física. 2017. 131 f. Dissertação (Mestrado em Educação) - Universidade Metodista de Piracicaba, Piracicaba, 2017. Disponível em: <https://www.unimep.br/phpg/bibdig/pdfs/docs/05052017_150355_biancagranzoto_ok. pdf>. Acesso em: 20 nov.2018.

HOFFMANN, M. B.. Constituição da identidade profissional docente dos formadores de professores de biologia: potencialidades da intercoletividade. 2016. 317 f. Tese (Doutorado em Educação Científica e Tecnológica) - Universidade Federal de Santa Catarina, Florianópolis, 2016. Disponível em:

$<$ https://repositorio.ufsc.br/xmlui/bitstream/handle/123456789/176680/345409.pdf?sequ ence $=1 \&$ isAllowed $=\mathrm{y}>$. Acesso em: 20 nov.2018

KASSEBOEHMER, A. C.; FARIAS, S. A.. Conteúdos das disciplinas de interface atribuídos a prática como componente curricular em cursos de licenciatura em Química. Alexandria: Revista de Educação em Ciência e Tecnologia, Florianópolis, v. 5, n. 2, p. 95-123, set. 2012. ISSN 1982-5153. Disponível em: <https://periodicos.ufsc.br/index.php/alexandria/article/view/37716>. Acesso em: 26 nov. 2018. doi:https://doi.org/10.5007/\%x.

LEAL, M. F. C.. Teoria e prática no processo de formação profissional: o caso de um curso de licenciatura em Matemática. 2016. 235 f. Tese (Doutorado em Educação Matemática) - Pontifícia Universidade Católica de São Paulo, São Paulo, 2016.

Disponível em:

$<$ https://sapientia.pucsp.br/bitstream/handle/18951/2/Maria\%20de\%20Fatima\%20Costa \%20Leal.pdf>. Acesso em: 20 nov.2018 
MAFFEI, W. S.. Prática como Componente Curricular e estágio supervisionado na formação de professores de Educação Física. Motrivivência, Florianópolis, v. 26, n. 43, p. 229-244, nov. 2014. ISSN 2175-8042. Disponível em:

$<$ https://periodicos.ufsc.br/index.php/motrivivencia/article/view/2175-

8042.2014v26n43p229>. Acesso em: 26 nov. 2018. doi:https://doi.org/10.5007/2175$8042.2014 \mathrm{v} 26 \mathrm{n} 43 \mathrm{p} 229$.

MELO, J. S.. A prática como componente curricular na formação de professores de química e física da UESC. 2018. 116 f. Dissertação (Mestrado em Educação em Ciências) - Universidade Estadual de Santa Cruz, Ilhéus, 2018. Disponível em: <http://www.biblioteca.uesc.br/biblioteca/bdtd/201610056D.pdf >. Acesso em: 20 nov. 2018

MONTEIRO, F. O. M.. A prática como componente curricular na formação de professores do curso de licenciatura em biologia do IFPI campus Floriano. 2013. 130 f. Dissertação(Mestrado em Educação) - Universidade do Vale do Rio dos Sinos, São Leopoldo, 2013. Disponível em:

<http://www.repositorio.jesuita.org.br/bitstream/handle/UNISINOS/3452/Francisca\%20 Monteiro.pdf? sequence $=1 \&$ isAllowed=y $>$. Acesso em: 20 nov.2018

MOREIRA, C. H. P.. A contextualização no âmbito da prática como componente curricular de genética. 2017. 188 f. Dissertação (Mestrado em Ensino das Ciências) Universidade Federal Rural de Pernambuco, Recife, 2017. Disponível em: <http://www.tede2.ufrpe.br:8080/tede2/bitstream/tede2/7428/2/Cesar\%20Henrique\%20 Pinto\%20Moreira.pdf>. Acesso em: 20 nov.2018

NASCIMENTO, A. P.. Mil horas para quê? A prática como componente curricular na Licenciatura em História. Antíteses, Londrina, PR, vol. 6, n. 12, p. 35-52, dez. 2013. ISSN: 1984-3356. Disponível em:

<http://www.uel.br/revistas/uel/index.php/antiteses/article/view/17179/13551>. Acesso em: 26 nov. 2018. doi:http://dx.doi.org/10.5433/1984-3356.2013v6n12p35

OLIVEIRA, M. G.. A prática como componente curricular na perspectiva da formação inicial do professor de geografia para a educação básica. $2015.170 \mathrm{f}$. Dissertação (Mestrado em Educação) - Universidade Estadual do Oeste do Paraná, 
Francisco Beltrão, 2015. Disponível em:

<http://tede.unioeste.br/bitstream/tede/969/1/Morgana_Garda.pdf>. Acesso em: 20 nov.2018

OLIVEIRA-NETO, J. F.. Configurações da prática como componente curricular nos cursos de licenciatura em ciências biológicas de universidades públicas em Goiás: sentidos e implicações. 2016. Dissertação (Mestrado em Educação em Ciências e Matemática) - Universidade Federal de Goiás, Goiânia, 2016. Disponível em: $<$ https://repositorio.bc.ufg.br/tede/bitstream/tede/5881/5/Disserta\%C3\%A7\%C3\%A3o \%20-\%20Jos\%C3\%A9\%20Firmino\%20de\%20Oliveira\%20Neto\%20-\%202016.pdf >. Acesso em: 20 nov.2018

OMELCZUK, A. B.. Prática como Componente Curricular - Definições legais e sua expressão na Formação Inicial do Professor de Ciências e Biologia. 2017.

Dissertação (Mestrado em Educação em Ciências Química da Vida e Saúde) Universidade Federal de Santa Maria, Santa Maria, 2017. Disponível em: <https://repositorio.ufsm.br/bitstream/handle/1/13669/DIS_PPGEC_2017_OMELCZU K_ALINE.pdf?sequence $=1 \&$ is Allowed $=\mathrm{y}>$. Acesso em: 20 nov.2018

PEREIRA, B.. Entre concepções e desafios: a prática pedagógica como componente curricular na perspectiva de professores universitários de ciências biológicas. 2016. 133 f. Dissertação (Mestrado em Educação Científica e Tecnológica) - Universidade Federal de Santa Catarina, Florianópolis, 2016. Disponível em: $<$ https://repositorio.ufsc.br/bitstream/handle/123456789/172254/343059.pdf?sequence= 1\&isAllowed=y>. Acesso em: 20 nov.2018

PEREIRA, M. S.; VELASCO, P. D N.. Práticas de ensino e formação docente: notas sobre a experiência da Licenciatura em Filosofia da UFABC. Educação (UFSM), Santa Maria, RS, vol. 40, n. 1, p. 37-52, jan/abr. 2015. ISSN 1984-6444. Disponível em: <https://periodicos.ufsm.br/reveducacao/article/view/15967/pdf >. Acesso em: 26 nov. 2018. doi:http://dx.doi.org/10.5902/1984644415967.

PREUSSLER, R.. Formação de professores de matemática: a proposta integradora da prática como componente curricular no IFFAR. 2017. 209 f. Tese (Doutorado em Educação) - Fundação Universidade de Passo Fundo, Passo Fundo, 2017. Disponível 
em: <http://tede.upf.br/jspui/bitstream/tede/1219/2/2017RobertoPreuslerTese.pdf>. Acesso em: 20 nov.2018

RESENDE, M. H.. Análise dos aspectos pedagógicos da formação do professor de educação física: um estudo nas IES públicas de Minas Gerais. 2015. 127 f.

Dissertação (Mestrado em Educação Física)- Universidade Federal do Triângulo Mineiro, Uberaba, 2015. Disponível em:

$<$ http://bdtd.uftm.edu.br/bitstream/tede/321/5/Dissert\%20Marcia\%20H\%20Resende.pdf >. Acesso em: 20 nov.2018

ROCHA, H. N. B.. A prática como componente curricular na formação inicial do professor de matemática: um olhar na perspectiva da legislação brasileira. 2016. 200 f. Dissertação (Mestrado em Educação em Ciências e em Matemática Instituição de Ensino) - Universidade Federal do Paraná, Curitiba, 2016. Disponível em:

<https://acervodigital.ufpr.br/bitstream/handle/1884/45056/R\%20-\%20D\%20-\%20HAL LAYNE\%20NADAL\%20BARBOZA\%20ROCHA.pdf? sequence=1\&isAllowed=y $>$. Acesso em: 20 nov.2018.

RODRIGUES, N. C.; HENTZ, M. I. B.. Desafios da formação de professores de língua portuguesa: a relação entre os saberes disciplinares e os saberes da prática. Fórum Linguístico, Florianópolis, v. 8, n. 1, p. 55-73, abr. 2011. ISSN 1984-8412. Disponível em: 〈https://periodicos.ufsc.br/index.php/forum/article/view/1984-8412.2011v8n1p55>. Acesso em: 26 nov. 2018. doi:https://doi.org/10.5007/1984-8412.2011v8n1p55.

SANTOS, A. J. S.. A prática como componente curricular e o estágio supervisionado na concepção dos licenciandos: entre o texto e o contexto. 2017. 110 f. Dissertação (Mestrado em Química) - Universidade Federal de Goiás, Goiânia, 2017. Disponível em: <https://repositorio.bc.ufg.br/tede/bitstream/tede/7259/5/Disserta\%C3\%A7\%C3\%A3o $\% 20-\% 20$ Alan\%20Jhones\%20da\%20Silva\%20Santos\%20-\%202017.pdf >. Acesso em: 20 nov. 2018

SANTOS, A. J. S.; MESQUITA, N. A. S.. A Prática como Componente Curricular e o Estágio Supervisionado na Concepção dos Licenciandos: Entre o Texto e o Contexto. Revista Virtual de Química, Niterói, RJ, vol. 10, n. 3, p. 487-501, 2018. ISSN 1984- 
6835. Disponível em: < http://rvq.sbq.org.br/imagebank/pdf/v10n3a05.pdf >. Acesso em: 26 nov. 2018. doi: 10.21577/1984-6835.20180037.

SARRO, L. C. S.. A prática como componente curricular da licenciatura em matemática: sugestões de professores da educação básica. 2014. 119 f. Dissertação (Mestrado em Educação) - Universidade Metodista de Piracicaba, Piracicaba, 2014. Disponível em:

<https://www.unimep.br/phpg/bibdig/pdfs/docs/24022015_152210_luciane.pdf>. Acesso em: 20 nov.2018

SILVA, A. M. P. M.. A prática como componente curricular na formação do professor de biologia: contribuições? 2013. 116 f. Dissertação (Mestrado em Ensino das Ciências) - Universidade Federal Rural de Pernambuco, Recife, 2013. Disponível em: <www.tede2.ufrpe.br:8080/tede2/handle/tede2/5408>. Acesso em: 20 nov. 2018.

SILVA, A. M. P. M; JÓFILI, Z. M. S.; CARNEIRO-LEÃO, A. M. A.. A prática como componente curricular na formação do professor de Biologia: avanços e desafios na UFRPE. Amazônia: Revista de Educação em Ciências e Matemáticas, [S.1.], v. 10, n. 20, p. 16-28, jun. 2014. ISSN 2317-5125. Disponível em: $<$ https://periodicos.ufpa.br/index.php/revistaamazonia/article/view/2295>. Acesso em: 26 nov. 2018. doi:http://dx.doi.org/10.18542/amazrecm.v10i20.2295.

SILVA, M. R. L.. A Prática como Componente Curricular Via Projeto Integrado de Prática Educativa (PIPE) no Ensino de Estatística na Universidade: implementação e implicações na Formação inicial do Professor de Matemática. 2016. 520 f. Tese (Doutorado em Educação Matemática) - Universidade Estadual Paulista Júlio De Mesquita Filho/Rio Claro, Rio Claro, 2016. Disponível em: <http://hdl.handle.net/11449/138278>. Acesso em: 20 nov.2018

SILVERIO, L. E. R.. As práticas pedagógicas e os saberes da docência na formação acadêmico-profissional em Ciências Biológicas. 2014. 485 f. Tese (Doutorado em Educação Científica e Tecnológica) - Universidade Federal de Santa Catarina, Florianópolis, 2014. Disponível em: <https://repositorio.ufsc.br/xmlui/bitstream/handle/123456789/123393/327454.pdf?sequ ence $=1 \&$ isAllowed $=\mathrm{y}>$. Acesso em: 20 nov. 2018 
TAGLIATI, J. R.. Um estudo sobre as configurações curriculares e potenciais formativos de cursos de licenciatura em Física do estado de Minas Gerais. 2013. 212 f. Tese (Doutorado em Educação para a Ciência) - Universidade Estadual Paulista Júlio de Mesquita Filho/Bauru, Bauru, 2013. Disponível em: $<$ https://repositorio.unesp.br/bitstream/handle/11449/102056/tagliati_jr_dr_bauru.pdf?s equence $=1 \&$ isAllowed $=\mathrm{y}>$. Acesso em: 20 nov. 2018

VIANA, G. M.. Construção de relações teoria-prática na formação de professores de Ciências e Biologia. 2014. 319 f. Tese (Doutorado em Educação) - Universidade Federal de Minas Gerais, Belo Horizonte, 2014, Disponível em: <http://www.bibliotecadigital.ufmg.br/dspace/bitstream/handle/1843/BUBD9VFFZ4/tese__gabriel_viana__vers_o_final.pdf?sequence=1>. Acesso em: 20 nov. 2018

VIANA, G. M.; MUNFORD, D.; FERREIRA, M. S.; FERNANDES, P. C.. Relações teoria-prática na formação de professores de Ciências: um estudo das interações discursivas no interior de uma disciplina acadêmica. Education Policy Analysis Archives, [S.1], vol. 23, n. 1, p. 100, out. 2015. ISSN 1068-2341. Disponível em: <https://epaa.asu.edu/ojs/article/view/2049>. Acesso em: 26 nov. 2018. doi:http://dx.doi.org/10.14507/epaa.v23.2049

VIANA, G. M.; MUNFORD, D.; FERREIRA, M. S.; MORO, L.. Relações entre teoria e prática na formação de professores: investigando práticas sociais em disciplina acadêmica de um curso nas ciências biológicas. Educação em Revista, Belo Horizonte, MG, vol. 28, n. 4, p.17-49, dez. 2012. ISSN 1982-6621. Disponível em: <http://www.scielo.br/pdf/edur/v28n4/02.pdf>. Acesso em: 26 nov. 2018 VILLANI, M. K.. Licenciatura em matemática a distância na modalidade on line: um estudo sobre um curso da Universidade Aberta do Brasil. 2014. 385 f. Tese (Doutorado em Educação Matemática) - Universidade Anhanguera de São Paulo, São Paulo, 2014. Disponível em: <https://repositorio.pgsskroton.com.br/bitstream/123456789/3487/1/MARCELO\%20K RUPPA\%20VILLANI.pdf > . Acesso em: 20 nov.2018 
ZABEL, M.; MALHEIROS, A. P. S.. Prática como Componente Curricular: entendimentos, possibilidades e perspectivas. Educação Matemática Pesquisa: Revista do Programa de Estudos Pós-Graduados em Educação Matemática, [S.1.], v. 20, n. 1, maio. 2018. ISSN 1983-3156. Disponível em:

<https://revistas.pucsp.br/emp/article/view/34772>. Acesso em: 26 nov. 2018. doi:https://doi.org/10.23925/1983-3156.2018v20i1p128-146. 